\title{
*Mesut SIRRI
}

Orcid No: 0000-0001-9793-9599

\section{**Cumali ÖZASLAN}

Orcid No: 0000-0002-8660-5451

\section{****Mehmet FİDAN}

Orcid No: 0000-0002-0255-9727

*Siirt Üniversitesi, Kurtalan Meslek

Yüksekokulu, Bitkisel ve Hayvansal

Üretim Bölümü (Sorumlu yazar)

**Dicle Üniversitesi, Ziraat Fakültesi,

Bitki Koruma Bölümü

***Siirt Üniversitesi, Fen Edebiyat

Fakültesi, Biyoloji Bölümü

m.sirri@siirt.edu.tr

\section{DOI}

https://doi.org/10.46291/ISPECJ ASvol4iss4pp806-820

Geliş Tarihi: $15 / 10 / 2020$

Kabul Tarihi: 10/11/2020

\section{Anahtar Kelimeler \\ Parazit yabancı otlar, konukçu bitkiler, flora}

\section{Keywords}

Parasitic weeds, host plants, flora

\section{Siirt'te Doğal Yayılıs Gösteren Parazit Yabancı Otlar ve}

\section{Konukçuları}

Özet

Bitkisel üretimde ekonomik verim kaybına neden olan en önemli faktörlerden birisi de yabancı otlardır. Yabancı otlar kültür bitkileri ile rekabete girerek ve allelopatik etkileri ile kültür bitkilerini olumsuz etkilemeleri yanında kültür bitkileri üzerinde parazit olarak yaşamak suretiyle verim ve kalite kayıplarına neden olmaktadırlar. Çalışma ile Siirt ili genelinde görülen parazitik yabancı ot türlerinin ve rastlanma sıklıklarının belirlenmesi amaçlanmıştır. Sürvey çalışmaları 2018-2019 yıllarında ve ili temsil edecek şekilde toplam 105 noktada yürütülmüştür. Çalışmalar sonucunda tam parazitik karekter gösteren Orabanche cinsine ait 3 tür (Orobanchea egyptiaca Pers., Orobanche crenata Forssk. ve Orobanche ramosa L.), Cuscuta cinsine dahil 2 tür (Cuscuta approximata Bab., Cuscuta campestris Yunck.) saptanmıştır. Ayrıca bölgede ormanlık alanlarda meşe türlerinde sorun olan ve yarı parazitik nitelik gösteren Viscum album L. ve Loranthus europaeus Jacq. türlerine de rastlanmıştır. Bölgede belirlenen parazitik yabancı otlara konukçuluk yapan kültür bitkileri ile yabancı otlar da listelenmiştir. Tarımsal açıdan Orobanche türlerine özellikle mercimek ve domates tarlalarında sıklıkla rastlandığı ve önemli düzeyde ekonomik kayıplara neden oldukları saptanmıştır. Bölgede parazit yabancı otlardan kaynaklanan verim kayıplarının önlenmesi için entegre yabancı ot idare stratejilerine ihtiyaç duyulduğu görülmüştür. Ancak üreticilerin konuya ilişkin bilgi birikimlerindeki eksiklik dikkate alınarak öncelikle konuya ilişkin yayım çalışmalarının öncelikle yapılması gerektiği kanaatine varılmıştır.

\section{Parasitic Weed Species and Their Hosts in Siirt Province of Turkey}

\section{Abstract}

Weeds are among the most important factors that cause economic losses in crop production. Weeds cause yield and quality losses by competing with crops and negatively affecting them with their allelopathic effects. In addition, some weeds live as parasites on crop plants. The study aimed to determine parasitic weed species and their incidence in Siirt province of Turkey. Survey studies were carried out in a total of 105 points representing the province, in 2018-2019. A total of 7 parazitik weeds species (Orobanchea egyptiaca Pers., Orobanche crenata Forssk., Orobanche ramosa L., Cuscuta approximata Bab., Cuscuta campestris Yunck., Viscum album L. and Loranthus europaeus were identified in the region. The crops and weeds hosts of the parasitic weeds were also determined. It has been observed that the incidences of Orobanche species were quite high especially in lentil and tomato fields and were cause significant economic losses. It has been also observed that integrated weed management strategies are needed to prevent yield losses by parasitic weeds in the region. However, considering the deficiency of the knowledge of producers on the subject, it was concluded that farmer awareness programs are urgently needed. 


\section{GíRIŞ}

Modern tarım sistemlerinde sürdürülebilir bir üretim için bitki koruma önlemleri bir zorunluluk olarak görülmektedir. Zira dünya genelinde her yıl zararlı ve patojenlerden oluşan verim kayıplarının sırasıyla \%18 ve \%16 seviyelerine ulaşabildiği belirtilmektedir. Yabanc1 otlardan kaynaklı verim kayıplarının ise yaklaşık olarak hastalık ve zararlıların toplamına (\%34) eşit olduğu hesaplanmaktadır (Oerke, 2006; Gharde ve ark., 2018). Bununla birlikte yabancı otlardan kaynaklanan verim kayıplarının coğrafi bölgelere ve kültür bitkilerine göre farklılık gösterdiği bildirilmektedir (Önen ve ark., 2012). Nitekim şekerpancarı gibi bazı kültür bitkilerinde yabancı ot mücadelesi yapılmadiğında bu oran \%90'nın üstüne çıkabilmektedir (Önen, 1995). Dolayısıyla yabancı otlardan kaynaklanan kayıpların global düzeyde ekonomik maliyetinin yıllık olarak 100 milyar dolardan fazla olduğu bildirilmektedir. Yabancı ot mücadelesi amaciyla kullanılan girdi maliyetlerinin (herbisitler) ise yaklaşık 25 milyar dolar olduğu düşünülmektedir (Gharde ve ark., 2018). Bu nedenle yabanc1 ot mücadelesi başarılı bir üretim için vazgeçilmez unsurlar arasında yer almaktadır.
Ülkemizde yabancı otlardan kaynaklanan verim kayıplarının ise \%50'inin üstünde olduğu belirtilmektedir (Tepe, 1998). Ancak kültür bitkisine göre bu kayıpların değişiklik gösterdiği ve hububatta yabancı otlardan kaynaklanan kayıpların \%20-30, şeker pancarında \%6-40, pamukta \%21-61, ayçiçeğinde $\% 15-100$, sebzelerde $\% 10$ ve nohutta\%15-24 olduğu ifade edilmiştir (Güncan ve Karaca, 2018). Yabanc1 otlardan kaynaklanan bu kayıplar sadece rekabet nedeniyle oluşmamaktadır. Rekabetin yanında yabancı otlar allelopatik etkileriyle kültür bitkilerinin gelişimini engelleyerek ve kültür bitkileri üzerinde parazitik olarak gelişerek de önemli verim kayıplarına neden olmaktadırlar (Özer ve ark., 2003; Önen, 2006). Tarımsal üretimde sorun oluşturan en önemli parazit yabancı ot türlerinin; Orabanche, Cuscuta, Viscum ve Striga cinslerine dahil olduğu görülmekte ve bu türlerin dünya genelinde olduğu gibi ülkemizde de çok büyük verim kayıplarına neden olabildikleri bilinmektedir. Konukçu kültür bitkisine göre oluşan kayıplarda farklılık görülmesine rağmen parazitik yabancı otlardan kaynaklanan verim kayıplarının \%5-100 arasında olduğu belirtilmektedir (Mohamed ve ark., 2014). Yaşam stratejileri nedeniyle diğer yabancı otlardan ayrılan parazitik yabancı otlarla 
mücadelede farklı stratejilere ihtiyaç duyulmaktadır. Ancak genel olarak başarılı bir yabancı ot kontrolü için öncelikle sorun olan türlerin ve bunların yaygınlıklarının belirlenmesi gerekmektedir. Bu düşünceden yola çıkılarak çalışmayla Siirt ili genelinde sorun olan parazitik yabancı otların belirlenmesi ve bunların tanitılması hedeflenmiştir.

\section{MATERYAL ve YÖNTEM}

Çalışma alanını oluşturan Siirt ilinin yüzölçümü 562.705 ha olup sahip olduğu toplam alanın \%18'lik kısmında yani 102.894 hektarda tarımsal üretim yapılmaktadır. Tarımsal üretim deseni olarak hububat (39.650 ha), meyvelik alan (26.450 ha) ve diğerleri (sebzelik, bağ, baklagil, yem bitkiler ve nadas alanlar) oluşturmaktadır (Anonim, 2019). Siirt ili genel olarak karasal iklime sahip olup güney ve güneybatı bölgelerinde yazlar sıcak ve kurak, kışlar ise 1 lık ve yağışlı geçerken, doğu ve kuzey bölgelerinde ise kışlar daha sert ve yağışlıdır. Çalışmada temel olarak Siirt florasında bulunan parazit yabancı ot türleri ve konukçularının belirlenmesi hedeflenmiştir. Dolayısıyla araştırma alanında tarım ve tarım dışı alanlarda sorun olan parazit yabancı otlar çalışmanın ana materyalini oluşturmuştur. Çalışma kapsamında 2018-2019 yılları arasında tarım ve tarım dışı alanlarda arazi sürveyleri yapılmıştır. Arazi çalışmalarında kültür bitkileri ve parazitik yabancı otların biyolojik özellikleri de dikkate alınarak Mart-Ekim ayları arasında gerçekleştirilmiştir. Sürvey çalışmalarında bölgeyi temsil edecek şekilde ve il/ilçelerdeki ana yollar esas alınarak yaklaşık 10 km'de durulup alanın parazitik yabancı otlar yönüyle gözden geçirilmesi suretiyle yapılmıştır. Tesadüfen durulan her örnekleme noktasında bulunan; bahçeler (antepfistığı, ceviz, badem, üzün ve nar vb) ve sebze alanları (domates, patlican, salatalık, biber, marul, lahana vb), tarla tarımı yapılan alanlar (buğday, mercimek, pamuk, nohut, yonca, fiğ, arpa vb) alanları gözden geçirilmiştir. Örnekleme noktalarında tarım alanları yanında tarım dışı alanlarda (yol ve su kanal kenarları, döküntü alanlar, mera ve ormanlık alanlarda) da gözlem yapılmıştır. Arazi çalışmalarında tespit edilen parazit yabancı otların resimleri çekilmiş, herbaryum için örnek alınmış ve konukçu bitki türleri kaydedilmiştir. İl genelinde toplam 105 noktada sürvey çalışmaları yapılmıştır.

\section{BULGULAR VE TARTIŞMA}

Sürvey çalışmaları toplam 105 noktada gerçekleştirilmiş olup 54 lokasyonda parazit yabancı otlardan en azından birine 
rastlanmıştır. Dolayısıyla parazitik yabancı otların (en az biri) rastlanma sıklığı \%49,5 olarak hesaplanmıştır. Çalışma alanında Cuscutaceae (2 tür), Orobanchaceae (3 tür) Loranthaceae (1 tür) ve Santalaceae (1 tür ) olmak üzere 4 familyadan toplam 7 parazit yabancı ot türü tespit edilmiştir. Çalışma alanında belirlenen parazitik yabancı otlar ve genel özellikleri özet halinde aşağıda verilmiştir.

\section{Cuscuta approximata Bab. (Bağboğan} otu): Gövdesi ince veya orta kalınlıkta olup çiçekleri 2,5-4 mm uzunluktadır. Kaliks (çanak yaprak) korollayı kapsamakta, loblar triangular-ovat, az veya çok sert uçlu, etli fakat belirgin bir şekilde şişkinlik yok, kaliksin alt kısımları genellikle sarı renklidir. Meyveler olgunlaştığında küre şeklini almaktadır. Loblar; ortalama tüp kadar veya daha kısadır. Pullar; tüpten daha kısa fakat stamenlere ulaşır durumda, dikdörtgen, düz veya iki bölmeye ayrılmış, azda olsa uçta püsküllüdür. Stigma ise ortalama stilus kadardır. Kapsül, basık küre şeklindedir (Şekil 1). Tohumlar, ortalama11,5 mm uzunluğunda, yüzeyi belirgin bir şekilde skabrosdur (Davis, 1978; Kaya ve ark., 2018).

Cuscuta campestris Yunck. (Kafir saçı): Gövdesi genellikle ipliksi yapıda, çiçekleri ise 2-3 mm uzunlukta olmaktadır. Çiçek sapları çoğunlukla çiçekten daha kısa ve yoğun küremsi- salkım şeklindedir. Kaliks (çanak yaprakları) neredeyse korolla tüpünü kaplar, korolla lobları ise oval, orbicular ya da bazen genişlik uzunluktan daha fazla, loblar üst üste gelmiş durumdadır (Şekil 1). Korolla lobları genişçe triangular, akut, genelikle kıvrılmış ve loblar kampanulat, tüpten daha kısadır. Filamentler ise; korolla loblarından daha uzun veya eşittir. Staminalbrakterler (pullar); oval ve bolca püsküllüdür. Ovaryum; globos. Tohumlar; oval ortalama 1,3 $\mathrm{mm}$ uzunluğundadır (Davis, 1978; Özer ve ark., 1999; Kaya ve ark., 2018).

Orobanche ramosa L. (Narin canavarotu): Bitki kök parazitidir. Gövdesi tüylü olup dik büyür ve alttan dallanır. Çiçekleri menekşe renklidir. Boyları ortalama olarak 19-27 cm uzunluğunda ve 2-7 $\mathrm{mm}$ çapındadır. Yaprakları genelde pulsu ve küçük yapılı olup boyu 0,9-1 mm, eni ise 3-4 mm'dir. Çiçekleri başak veya salkım şeklinde, her biri 1 brakteli bir çiçek konumundadır (ortalama 30 çiçekli). Kaliks 5 sepallidir, dişleri tüpten kısa genellikle uzun sivri uçlu ve alt dudağın lopları yuvarlağımsıdır. Korolla 14-16 mm uzunluğunda, tüylü, mor veya sarı renklidir (Şekil 1). Korolla bitişik petalli ve az çok kıvrık bir tüp veya çan 
şeklinde, iki dudaklı; alt dudak üç loplu, üst dudak ise iki lopludur. Silindirik şekilde öne doğru kıvrılmış ve dışı sarı, mor, turuncu içi ise mor veya koyu kahverenklidir. Stigma genellikle sarı veya turuncu rengindedir(Şekil 1).Stamen 4 didinamkorolla tüpüne çeşitli şekillerde bağlı ve ortalama olarak corolla boyuna eşit bir boydadır. Flamentlerde tabanda geniş, tepeye doğru daralmış şeklindedir. Antenler kısa aküminatlı, iki tekalı, tekalar tabanda yuvarlak, tepede sivrilmiştir. Polenler açık sarı renkte ve taneler küre şeklindedir. Meyveler kapsül şeklinde, 3-5 mm eninde ve 6-10 $\mathrm{mm}$ boyunda olmaktadır. Kapsül 2 valfli, bazen valfler stilüs tabanında birbirine bağl1, kaliks meyve etrafında kalıcıdır. Tohumla çok küçük, çok sayıda, yuvarlak veya dikdörtgenimsi bir şekildedir (Pelit, 2012).

\section{Orobanche}

aegyptiaca

Pers.

(Dinlendiren) : Bitkinin gövdesi $15-50 \mathrm{~cm}$, genellikle dallı, sarımsı, orta kısım 6-8 mm kadar kalınlıkta, tabana doğru hafif kalınlaşan, $15 \mathrm{~mm}$ uzunluğunda ovalmızraksı pullarla kaplıdır(Şekil 1).Kısa glandüller k1llarla kaplı olan bitki bazen neredeyse tüysüzdür. Çiçeklerin saplar üzerindeki duruşu silindirik, kolay kırılabilen, $25 \mathrm{~cm}$ kadar uzunlukta, sapın geri kalan kısmına eşit veya daha uzundur.
Taç yapraklar 25-35 mm uzunluğunda, huni şeklinde oldukça genişlemiş, neredeyse dik, mavi-mor veya gök mavisi, alt tabanı daha hafif beyazımsı, kısa, seyrek, glandüler kıllarla kaplı ve içi tüysüzdür. Kaliks (çanak) 8-14 mm uzunluğunda, genellikle çok hafif, beyazımsı, kısa, glandüler kıllarla kaplıdır. Bir bitki her yıl 1 milyondan fazla tohum üretir; tohumlar uygun koşullar altında topraktaki çimlenme kapasitelerini uzun süre muhafaza eder (Kabulov ve Mukumov, 1965; Anonim, 2020).

Orobanche crenata Forssk. (Zıpır otu): Gövde etli, dik, dallanmayan, 30-70 cm kadar boylanabilen, seyrek tüylü genellikle sarımsı bir çiçek sapından oluşur. Çiçekleri genellikle bir başak şeklinde ve yukarıya doğru yoğun çiçekli bir yapıdadır (Şekil 1). Corolla genellikle 20-30 mm uzunluğunda, subglabrous, beyazdır; 4 stamenscorolla tabanının 2-3 mm üzerinde yer alır. Brakte hemen hemen mizraksı, uzun ve ucu aniden sivrilen, s1k salgılı, cılız tüylü, sıklıkla beyaz-kaba tüylü, boyu genellikle tüp şeklindeki taç yapraklara eşittir. Çanak yapraklar iki parçalı veya iki dişli, çanak dişler dar, biz şeklinde veya ipliksi, nadiren mızraksı, 3 damarlı, birbirinden uzaklaşan; taç yaprakları 20-30 cm boyunda, beyaz veya soluk mavi-menekşe renginde ve tüysüzdür. Ercikler taç yaprak tabanından 
yukarıda 2-5 mm; sapçıklar sık, tabanda cılız tüylü, yukarıda salgılı-cılız tüylü, nadiren tüysüz; tepecik soluk, menekşe rengi veya mat eflatun renktedir. Meyveleri 10-12 mm uzunluğunda, çok sayıda, küçük ve kahverengi renktedir (Davis, 1978; Rustuccia ve ark., 2009).

\section{Loranthus europaeus Jacq. (Ardıç}

burcu): Bitki sürgünleri 1,3 m kadar uzanabilir. Kışın yaprağını döken yarı parazit bir bitkidir. İnternodlardan kolayca kırılabilen veya ayrılabilen, yuvarlak sürgünleri kahverengi ve parlaktır. Dallanması pseudodichotomie (yalanc1 çatallanma) şeklindedir. Yaprakları, genel olarak ters yumurta şeklinde, hafif ince, diktörgenimsi ve uzun, tam kenarlı ve küt uçludur. Renkleri koyu yeşildir (Şekil 1). Yapraklar karşılıklı, kalın kısa saplı, dip kısmı yuvarlak ve stipulasızdır. Yaprak boyutları homojen bir yap1 oluşturur ve ortalama 3,50-4,30 cm boyda, yaprak eni ise 0,80-1,15 cm'dir. Çiçek yapısı, terminal durumlu, erdiş veya monoiktir. Çiçek ekseninin alt kısmında çanak yaprağa benzer kısa ve dişli kalikulus bulunur ve birkaçı bir arada kurullar oluşturur. Taç yaprak sayısı 4 ile 6 arasında değişir. Taç yapraklar uzunca ve yeşile yakın sarı bir renkli ve serbesttir. Meyvesi, yumurta veya küre şeklinde olup dalla birleştiği yerde daralır ve sürgünlerin ucunda 1-5 tane olarak dala asılı olarak bulunur. Meyvelerin renkleri başlangıçta yeşil, olgunlaştığında ise sarı renge dönüşürler. Meyvenin etli kısmı yapışkan bir madde ile doludur. Ekzokarp yırtıldığında yapışkan madde etrafa yapışmaktadır. Meyve içerisinde genelde tek tohum bulunur ve ortalama olarak $1 \mathrm{~cm}$ boyutundadir (Ergun ve ark., 1994; Dutkuner, 1998).

Viscum album L. (Ökse otu): Bitkinin gövdesi kalın ve kısa yapılıdır. Sürgünler yuvarlak, genç sürgünler yeşil renkli ve yalancı çatallanma (pseudodichotomie) şeklinde dallanmaktadır. Sürgünler nodlarda çok kolay bir şekilde ayrılmakta veya kırılmaktadır. Yaprakların boyutları üzerinde bulunduğu konukçu türüne göre değişmekle beraber ortalama $0,50-6,50 \mathrm{~cm}$ boyunda ve $0,50-1,80 \mathrm{~cm}$ enindedir. Çiçekler küçük ve erselik veya monoiktir. Erken çiçekler dişi çiçeklerde daha büyük ve gösterişli yapıdadır. Dişi çiçekler ise 3-5 tanesi bir arada sapsiz ve salkım şeklindedir. Ovaryum alt durumlu, stigma kalın, şişkin, yastık gibi, stilus kısa, perigon dört parçalıdır. Çanak yapraklar bulunmaz. Taç yapraklar dört parçalı ve sarı-yeşil renklidir. Flamentleri yoktur. Taç yaprakların iç kısmına kaynaşmış durumdadır. Meyveleri, küçük, ortalama 
olarak nohut ya da bezelye tanesi boyutunda küre veya armut şeklinde etli şeffaf ve tek tohumludur. İlk başta renkleri yeşil iken, olgunlaşınca beyaz, sarımtırak-yeşil rengine dönüşür. Üzümsü meyvelerin formu değişkendir(Şekil 1). Genişliği biraz daha uzun ve stigma belirgindir. Çiçek ekseni de meyve oluşumuna katılmaktadır. Perikarp klorofil içerir. Ekzokarp genellikle kalın (etli) viskoz veya müsilajlı yapışkan bir madde ile dolu olup herhangi bir şekilde yırtıldığında içerisindeki yapışkan madde etrafa yapışmaktadır. Meyvenin içi genelde bir ya da nadir de olsa iki veya üç tohumludur. Meyveler ortalama $1 \mathrm{~cm}$ kadardır (Ergun ve ark., 1994; Dutkuner, 1998; Özer ve erk., 1999). Çalışma alanında tespit edilen ve yukarıda verilen parazitik yabancı otların rastlanma sıklıkları, yoğun olarak görüldükleri bazı noktaların koordinatları ve konukçuluk yapan bitkiler Çizelge 1'de verilmiştir.

Çizelge 1. Familyalarına göre Siirt florasında tespit edilen parazit yabancı ot türleri, rastlanma sıklıkları, yoğun olarak görüldükleri bazı noktaların koordinatları ve konukçuluk yapan bitkiler verilmiştir.

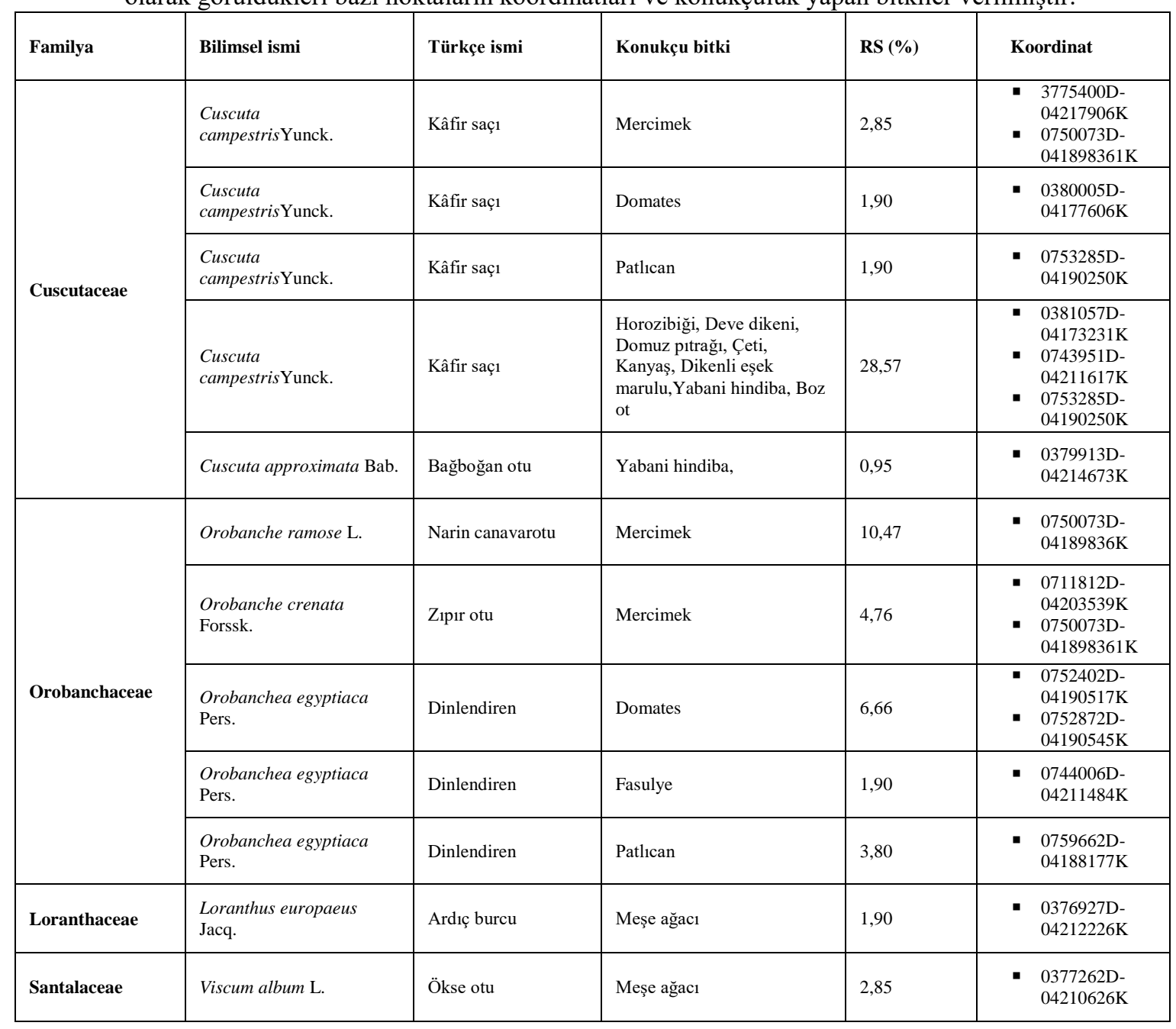


ISPEC Tarım Bilimleri Dergisi

2020 : 4(4)

(C) Telif hakk ISPEC'e aittir

Arastırma Makalesi
E-ISSN:2717-7238

:

www.ispecjournal.com
ISPEC Journal of Agr. Sciences

$2020: 4(4)$

Copyright (C) ISPEC

$\underline{\text { Research Article }}$

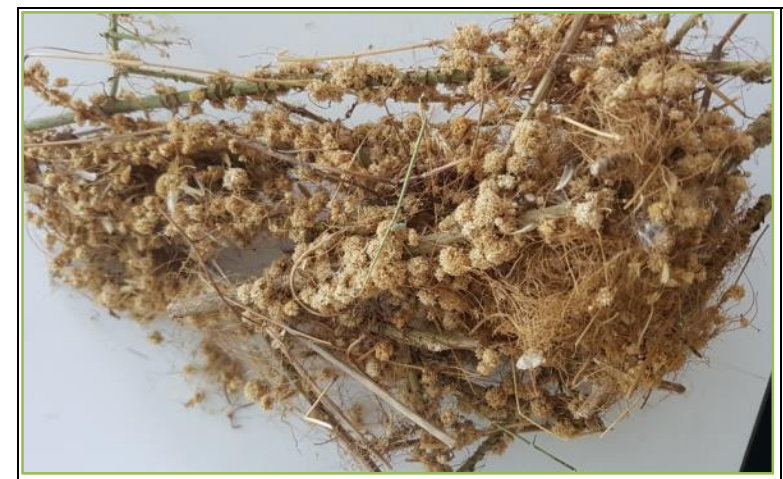

Cuscuta approximata

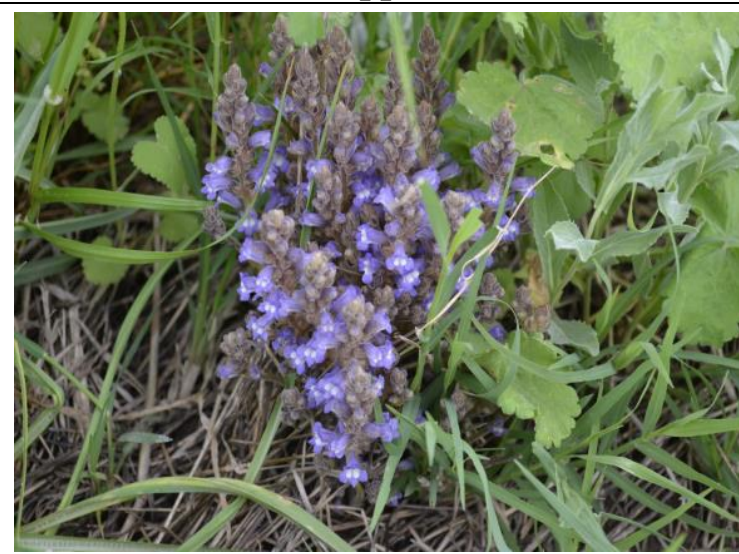

Orobanche ramosa

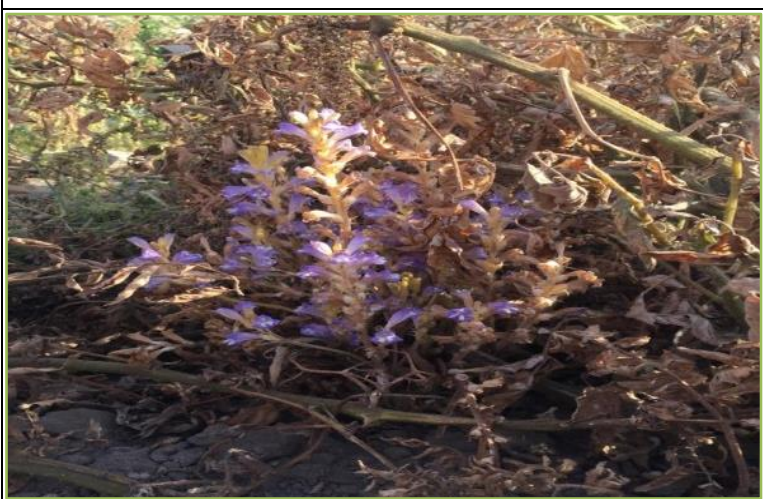

Orobanche aegyptiaca

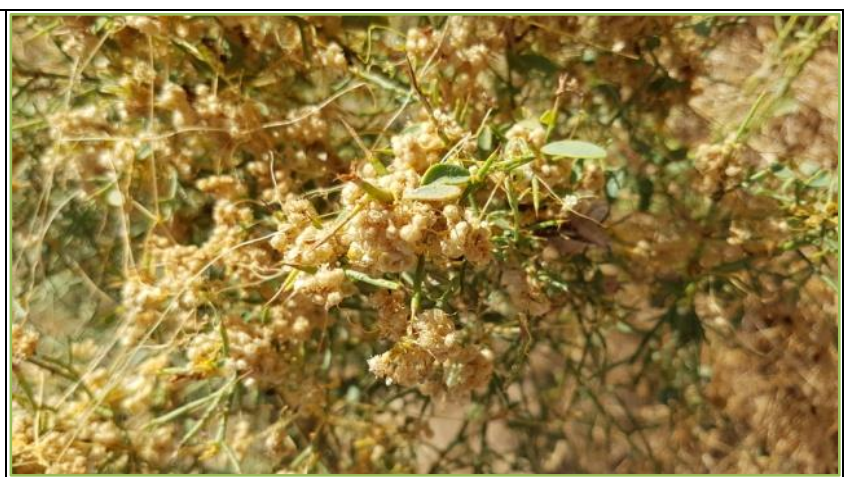

Cuscuta campestris

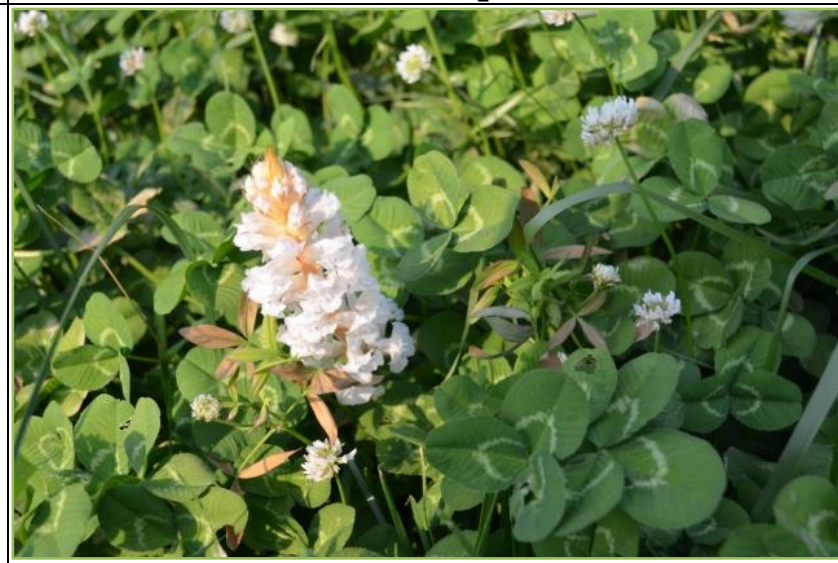

Orobanche crenata

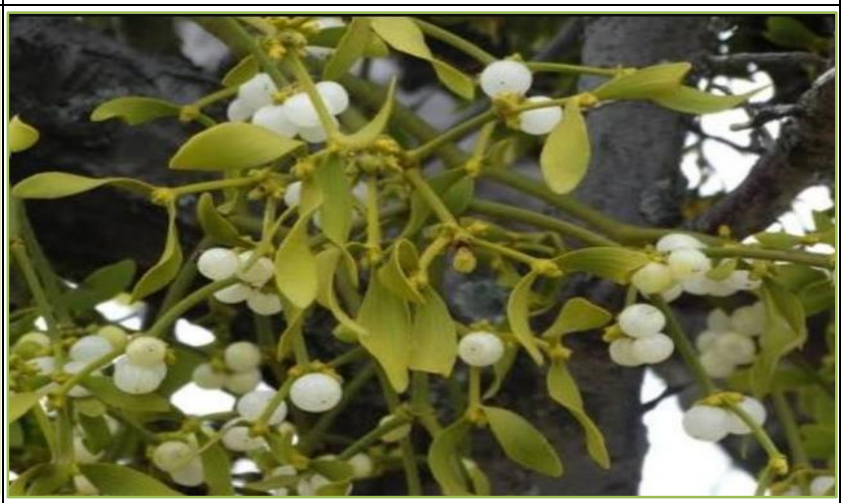

Viscum album 


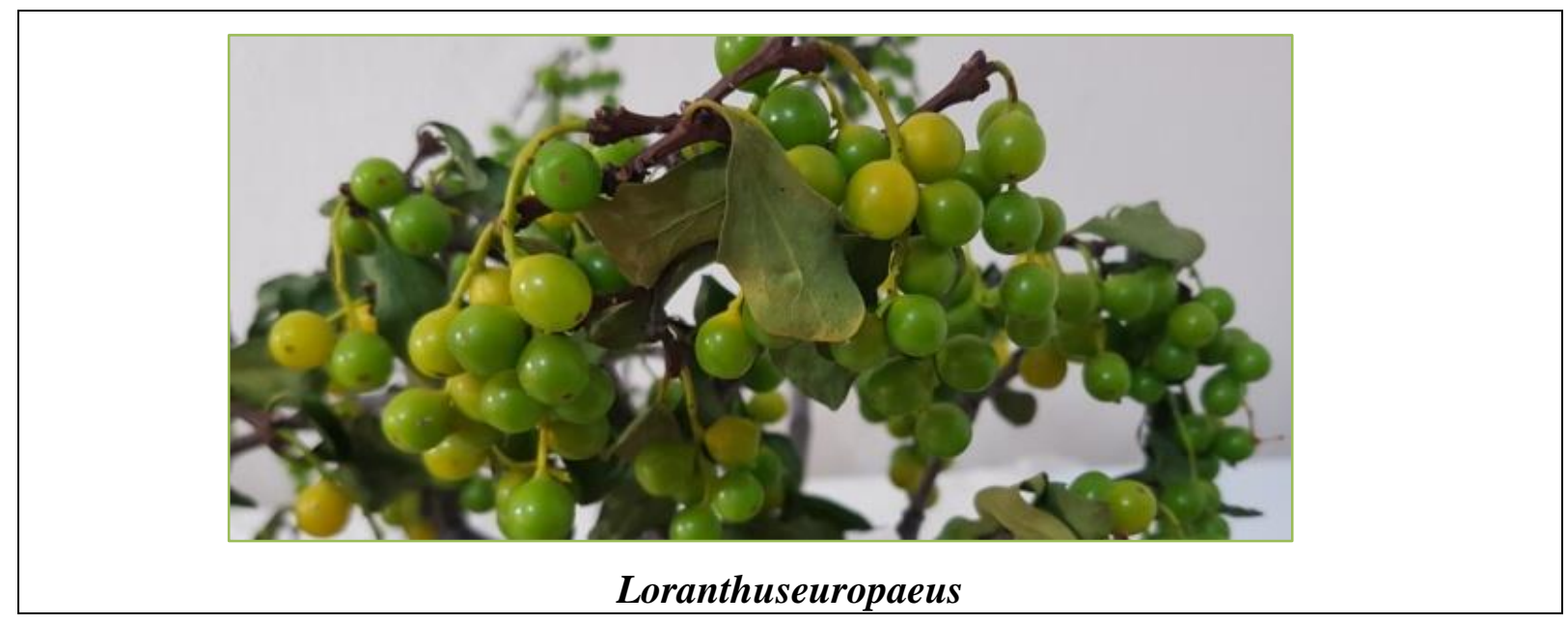

Şekil 1. Siirt ilinde tespit edilen parazit yabancı ot türleri

Çizelge 1 incelendiğinde çalışma alanında tespit edilen parazit yabanc1 otlar tarla bitkileri (mercimek), sebze (domates, patlıcan, biber, fasulye) ve meyve üretim alanları (bağ ve fistık), çayır-mera, ormanlık alanlar ve yol kenarlarında bulunabildiği görülmektedir. Bölgede Orobanche türlerine mercimek ve domates tarlalarında yoğun olarak rastlanmıştır. Ayrıca biber, patlıcan, fasulye ve tütün gibi kültür bitkilerinde de canavarotuna rastlanmıştır. Daha önce yapılan çalışmalarda da canavar otlarının genellikle Apiaceae, Asteraceae, Cucurbitaceae, Fabaceae ve Solanaceae gibi familyaya ait kültür bitkileri konukçu olarak tercih edildiği belirtilmiştir (Kadıŏlu, 2009; Sırrı, 2020). Yapılan gözlemlerde canavar otlarının özellikle domates ve mercimekte önemli düzeyde zarara yol açtığı gözlenmiştir. Üreticilerle yapılan görüşmelerde de canavar otunun domateste \%100'e varan üretim kayıplarına yol açabildiği ifade edilmiştir. Nitekim bu parazit yabanc1 otun dünya genelinde bulaşık olduğu kültür bitkisi ve bulaşma yoğunluğuna da bağlı olarak \%5-100 arasında zarara yol açabildiği ifade edilmiştir (Linke ve ark., 1989; Rubiales ve ark., 2009; Kadıŏlu, 2009; Aksoy ve ark., 2014). Canavar otundan dolayı ülkemizde domateste $\% 24$ oranında verim kaybının olduğu Aksoy (2010) dikkate alındığında canavar otunun bölge domates üretimi için önemli bir sorun olduğu anlaşılacaktır. Ülkemizde Orabanche ile ilgili yapılan çalışmalar parazit bitkinin yaygınlık ve yoğunluğu bölgelere göre değişkenlik arz etmektedir. Güneydoğu Anadolu bölgesinde mercimek tarlalarında $O$. 
crenata, $P$. aegyptiaca ve $P$. ramosa türü ile bulaşık olduğu genel yaygınlık oranının $\% 65$ ve tarlaların \%10'unun yoğun, \%25'inin ise çok yoğun bulaşık olduğu bildirilmiştir (Uludağ ve Demirci, 2005). Fakat canavar otu türlerinin ekolojik bölgelere göre yaygınlık ve yoğunluklarında farklılık olduğu görülmektedir. Nitekim yaygınlık oranlarının Diyarbakır'da \%5-100, Gaziantep'te \%74,36, Şanlıurfa'da \%41,90 ve Kilis’te $\% 53,85$ olduğu belirtilmiştir (Uludağ ve Demirci, 1997; Bayram, 2008; Aksoy, 2010; Aksoy ve ark., 2014; Aslan ve ark., 2017). Çalışma alanında yapılan gözlemlerde Cuscuta türlerinin tarım alanlarından çok tarım dişı alanlarda daha fazla yoğunluk oluşturdukları saptanmıştır. $\mathrm{Bu}$ durumun çalışma alanında hububat ağırlıklı ekim nöbeti uygulanmasının bir sonucu olduğu kanaatine varılmıştır. Zira küsküt genel olarak Asteraceae, Brassicaceae, Convolvulaceae, Fabaceae, Solonaceae ve diğer familyalarda ekonomik olarak zarar oluşturmaktadır (Kaya ve ark., 2018). C. campestris türü küresel ölçekte 27'si kültür bitkisi (patates, kavun, karpuz, şeker pancarı, sebzelik, yem bitkileri, kenevir vb) olmak üzere 55 konukçusu bulunduğu ve meydana getirdiği ekonomik kaybın \%50-90 arasında değiştiği belirtilmiştir (Nemli, 1978; Nemli, 1986; Parker ve Riches 1993; Dawson ve ark. 1994; Lianve ark., 2006; Nemli ve ark., 2015; Sirr1, 2020; Önen, 2020). Hindistan'da yapılan bir çalışmada ise küsküt türlerinden kaynaklanan kayıpların (yoğunluğa bağlı olarak), biberde \%60-65, fasulyede \%31-34, mercimekte \%87, nohutta \%86, domateste \%31-34 ve yonca bitkisinde \%60-70 seviyelerine ulaşan kayıpların olduğu ifade edilmektedir (Mishra, 2009). Dolayısıyla Özaslan ve ark. (2017) tarafından da belirtildiği üzere canavar otu türlerinin gelecekte bölgede daha büyük sorun olacağı düşünülmektedir. Daha önce yapılan çalışmalarda Cuscuta türlerinin tarımsal alanlar, çayır-mera, ormanlık alanlarda ve yol kenarları gibi tarım ve tarım dışı bütün ekolojilerde yayılışının olduğu belirlenmiştir (Özer ve ark., 1996; Özer ve ark., 1999; Önen, 2015). Tarımsal üretimde neden olduğu zarar oranı ise \%20-57 arasında değiştiği belirtilmiştir. Ancak Nemli ve Öngen (1982)'de tarafindan yapilan tarla denemelerinde küsküt zararının \%91'lere kadar ulaşabildiği rapor edilmiştir. Küsküt yabancı otun kültür bitkilerindeki rastlanma sıklıkları bölgenin ve kültür bitkisinin türüne bağlı olarak değişmektedir. Orta Karadeniz bölgesinde farklı dönemlerde 
şeker pancarı tarlalarında yapılmış olan çalışmalarda küskütün rastlanma sıklıkları Önen (1995)'te \%26-49 bulunurken, aynı bölgede Kadığlu ve ark. (2015)’te \%32-36 arasında olduğu saptanmıştır. Doğu Anadolu bölgesinde yonca alanlarında yürütülen bir çalışmada ilk biçimde küsküt rastlanma sıkılığı \%48 olurken ikinci biçimde ise bu oran $\% 32$ olarak tespit edilmiştir (Yıldırım ve Tepe, 2014). Dolayısıyla çalışma alanında hububat ağırlıklı ekim nöbeti yerine alternatif ürünlerin her geçen yıl yaygınlaştığı dikkate alındığında küsküt türlerinin gelecekte çok daha büyük sorun olabileceği düşünülmektedir. Bölgede tespit edilen diğer bir yarı parazit bitki ise Ardıç burcu (Loranthus europaeus Jacq.) ve Ökse otu (Viscum album L.) türleridir. Ökse otunun bölgede çoğunlukla ormanlık ve mera alanlardaki meşe ve palamut ağaçlarının üstünde bulunduğu tespit edilmiştir. Halk tababetinde de yararlanılan yarı parazitik bir tür olan ökse otunun konukçu dizisi oldukça geniştir (Özer ve ark. 2002). Bitki ayva, armut, badem, erik, elma, kiraz, kaysı, zerdali, vişne, çitlembik ve alıç gibi meyve ağaçlarında, çam, ladin ve köknar gibi iğne yapraklı orman ağaçları ile akasya, ıhlamur, kestane, dişbudak, karaağaç, gürgen, meşe, kavak, kızılağaç, söğüt vb kışın yaprağını döken ağaçlar üzerinde bulunmaktadır (Zeybek, 1958; Ergun ve ark., 1994; Özer ve ark., 1999; Kumbasli ve ark., 2011). Yukarıda bahsedildiği gibi ökse otuna bölgeden ziyade ormanlık alanlarda rastlanmıştır. Bölgede meyveliklerin nispeten genç ve bakımlı olmasının bu bitkinin yayılmasını önlediği düşünülmüştür (Özer ve ark., 1999; Özer ve ark., 2001).

\section{SONUÇ}

Parazit yabancı otlardan canavar otu türlerinin çalışma alanında özellikle mercimek ve domates yetiştiriciliği açısından ciddi sorunlar oluşturduğu ve önemli verim kaybına neden olduğu saptanmıştır. Gelecekte küsküt türleri ve ökse otunun da sorunlara yol açabileceği kanaatine varılmıştır. Diğer yandan parazitik yabancı otların idaresinde kimyasal mücadelenin etkinliğinin sınırlı kalması ve diğer mücadele yöntemlerini de (elle çekme, tuzak bitki, geç ekim, derin sürüm, münavebe, dayanıklı çeşit kullanma, solarizasyon, biyolojik mücadele vb.) tek başına yeterli, kolay ve ekonomik olmaması parazit yabancı otların kontrolünü zorlaştırmaktadır. $\mathrm{Bu}$ nedenle parazit bitkilerin yoğunluklarının kontrol altında tutulması ve popülasyonlarının yoğunluklarının düşürülmesi için entegre 
(farkl1 mücadele yöntemlerinin bir arada kullanılması) bir mücadelenin yapılmasının oldukça önemli olacağı kanısına varılmıştır. $\mathrm{Bu}$ nedenle de konuya ilişkin yayım faaliyetlerinin yöre üreticisine katk1 sağlayacağı düşünülmektedir.

\section{KAYNAKÇA}

Aksoy, E. 2010. Türkiye'deki canavar otları ve mücadelesi. TÜBİTAK 105G 080 nolu Ülkesel Canavar Otu Projesi Çıktısı Broşürü, Adana Zirai Mücadele Araştırma Enstitüsü, 27s.

Aksoy, E., Arslan, Z.F., Eymirli, S., Tetik, Ö., Bayraktar, ÖV., Armağan, G. 2014. Gaziantep ve Kilis illeri kırmızı mercimek tarlalarındaki canavar otlarının [Orobanche crenata Forsk. ve Phelipanch eaegyptiaca (Pers.)] yaygınlığı, yoğunluğu ve üreticilerin yabanc1 ot sorunlarına yaklaşımları. Bitki Koruma Bülteni, 54 (2): 115-132.

Anonim, 2019. https://siirt.tarimorman .gov.tr/Lists/SolMenu/Attachments/23/201 3-2017\%20Faaliyet \%20Raporu.pdf (Erişim tarihi: 11.05.2020).

Anonim, 2020. http://www.agroatla s.ru/en/content/weeds/Orobanche aegyp tiaca/index.html (E. Tarihi: 11.05.2020).

Arslan, Z.F., Altun, AA., Bilgili, A. 2017. Türkiye mercimek (Lens culinaris Medik.) üretimindeki yabancı ot sorunlarının dünü, bugünü ve yarın1Şanlıurfa. Türk Tarım-Gıda Bilim ve Teknoloji Dergisi, 5(11): 1312-1322.

Bayram, Y. 2008. Diyarbakır ve Mardin illerinde mercimek ve domateste zararlı olan canavar otu türleri (Orobanchespp.) ve Phytomyza orobanchia (Kaltenbach), 1864 (Diptera: Agromyzidae) 'nın bu türler üzerindeki etkinliğinin araştırılması. Harran Üniversitesi, Fen Bilimleri Enstitüsü, Yüksek Lisans Tezi, Şanlıurfa.

Davis, P.H. 1978. Flora of Turkey and the East Aegeanislands. Vol. 6, University of Edinburg, England.

Dawson, J.H., Musselman, L.J., Wolswinkel, P., Dorr, I. 1994. Biologyandcontrol of Cuscuta. Reviews Weed Science, 6: 265-317.

Dutkuner, İ. 1998. Marmara Bölgesi'nde bulunan loranthaceae familyas taksonlarının morfolojik özellikleri üzerine bir araştırma. Turkish Journal of Agriculture And Forestry, 23(4): 983-989.

Ergun, F., Deliorman, D., Şener, B. 1994. Viscum album (Ökse otu) (Loranthaceae) bitkisinin morfolojik özellikleri ve Türkiye'deki yayılışı hakkında bazı araştırmalar. OT Sistematik Botanik Dergisi 1(2): 47-62.

Gharde, Y., Singh, P.K., Dubey, R.P., Gupta, P.K. 2018. Assessment of yield and 
economic losses in agriculture due to weeds in India, Crop Protection 107: 12-18.

Gürcan, A., Karaca, M. 2018. Yabanc1 ot mücadelesi (Güncellenmiş ve İlaveli 4. Bask1), Selçuk Üniversitesi Ziraat Fakültesi, Konya, 334 s.

Kabulov, D.T., Mukumov, Kh.M. 1965. About species composition of host-plants of Egyptian Broomrape (Orobanche aegyptiaca Pers.) in Middle Asia. Nauchnyedokladyvyssheishkoly,Biologich eskienauki (Moscow: Vysshayashkola) 2: 111-116.

Kadıoğlu, İ. 2009. Canavar otunun (Orobanchespp.) tanımı, zararları ve mücadelesi. Türkiye Herboloji Dergisi, 12(2):1-6.

Kadıoğlu, İ., Doğar, G., Ciğer, Ü. 2015. Şeker pancarı ekim alanlarında görülen küsküt (Cuscuta campestrisYunck.)'ün tanımı, zararı ve yaygınlık durumu. İstilacı Bitkiler Çalıştayı, 22 Mayıs Tokat, 18 (3): 15-16.

Kaya, İ., Nemli, Y., Demir, İ. 2018. Türkiye'de tarım ve tarım dişı alanlarda görülen küsküt türlerinin (Cuscuta spp.) Taksonomik özellikleri, dağılışları ve konukçuları Turk J Weed Sci. 21(1):1-7.

Kumbasli, M., Keten, A., Beşkardeş, V., Makineci, E., Özdemir, E., Yılmaz, E., Zengin, H., Sevgi, O., Y1lmaz, HC.,
Çalışkan, S. 2011. Hostsand distribution of yellow mistletoe (Loranthuse uropaeus Jacq. (Loranthaceae)) on Northern StrandjasOakForests-Turkey, Scientific Research and Essays, 6(14): 2970-2975.

Lian, JY., Ye, WH., Cao, HL., Lai, Z.M., Wang, Z.M., Cai, C.X. 2006. Influence of obligate parasite Cuscuta campestris on thecommunity of its host Mikaniamicrantha. Weed Research, 46, 441-443.

Linke, K.H., Sauerborn, J., Saxena, MC. 1989. Orobanche fieldquide. University of Hohenheim, Germany, 41s.

Mishra, JS. 2009. Biology and managemant of cuscuta species, Indian Journal of Weed Science, 41: 1-11.

Mohamed, K., Papes, M., Williams, R., Benz, BW., Peterson, AT. 2006. Global Invasive potential of 10 parasitic witch weeds and related orobanchaceae. Royal Swedish Academy of Sciences, Ambio Vol. 35, No. 6, 281-288.

Nemli, Y. 1978. Çiçekli parazitlerden Cuscuta L.'nin Anadolu türleri üzerinde morfolojik ve sistematik araştırmalar. Ege Üniversitesi, Ziraat Fakültesi, Doçentlik Tezi, İzmir.

Nemli, Y. 1986. Anadolu'da kültür alanlarında bulunan küsküt türleri (Cuscuta spp.); yayılışları ve konukçuları üzerinde 
araştırmalar. Ege Üniversitesi Ziraat Fakültesi Dergisi, 23 (3), 11-21.

Nemli, Y., Kaya, İ., Tamer, ŞR. 2015. Cuscuta campestris. istilacı bitkiler Çalıştayı/InvasivePlantsWork, 22 Mayıs 2015, Tokat, 271-282.

Nemli, Y., Öngen, N. 1982. Türkiye'nin trakya bölgesi küsküt türleri (Cuscuta spp.) üzerinde taksonomik araştırmalar. Tübitak Doğa Bilim Dergisi, 6 (3): 147-154.

Oerke, EC. 2006. Crop losses to pests: centenary review. J. Agric. Sci. 144, 31-43.

Önen, H. 2020. Endüstriyel kenevirde hastalık, zararlı ve yabancı ot mücadelesi. Harf Yayınları, İstanbul. ISBN: 978-9758738-45-8

Önen, H. 1995. Tokat Kazova'da yetiştirilen şeker pancarlarında sorun olan yabancı otlar ile uygulanan farklı savaş yöntemlerinin verime olan etkileri üzerinde araştırmalar. Gaziosmanpaşa Üniversitesi, Fen Bilimleri Enstitüsü, Yüksek Lisans Tezi, Tokat.

Önen, H., Özgöz, E., Özer, Z. 2012. Toprak işleme yöntemlerinin buğdayda yabancı otlanmaya ve verime etkileri. Gaziosmanpaşa Üniversitesi. Ziraat Fakültesi Dergisi, 29(1): 99-104.

Önen, H., 2006. Türkiye'de pelin ve yoncanın allelopatik etkileri üzerinde yapılmış çalışmalara genel bir bakış.
Allelopati Çalıştayı (Türkiye'de allelopatinin kullanımı: Dün, bugün, yarın) bildiri kitab1 (Sunulu Bildiri), sayfa 3-23. Atatürk Bahçe Kültürleri Merkez Araştırma Enstitüsü, Yalova.

Önen, H. (Ed.). 2015. Türkiye istilac1 Bitkiler Katalogu. Ankara, Turkey: T.C. Gıda, Tarım ve Hayvancılık Bakanlığı, Tarımsal Araştırmalar ve Politikalar Genel Müdürlüğü, Bitki Sağlığı Araştırmaları Daire Başkanlığı. ISBN: 978-605-9175-050 .

Ozaslan, C., Farooq, S., Onen, H., 2017. Broomrape infestation in lentil crop and farmer knowledge on the management of parasitic weed species in Diyarbakır province, Turkey. 26th Asian Pacific Weed Science Society Conference, Kyoto Japan.

Özer, Z., Kadıoğlu, İ., Önen, H., Tursun, N. 2001. Herboloji (Yabancı Ot Bilimi). Gaziosmanpaşa Üniversitesi, Ziraat Fakültesi Yayınları No:20, Kitaplar Serisi No:10, Tokat, 263s.

Özer, Z., Önen, H., Tursun, N. Uygur, F.N. 1999. Türkiye'nin bazı önemli yabancı otları (Tanımları ve Kimyasal Savaşımları). Tokat: Gaziosmanpaşa Üniversitesi Ziraat Fakültesi Yayınları No:38 Kitap Serisi No:16.

Özer, Z., Tursun, N., Önen, H. 2002. Yabancı otlarla sağlıklı yaşam, 4 Renk 
Yayın Tanıtım Matbaacılık Ltd. Şti. No: 85/7 İskitler/ Ankara.

Özer, Z., Önen, H. Uygur, N.F. Koch, W. 1996. Farklı kültürlerde sorun olan yabancı otlar ve kimyasal savaşımları. Tokat: Gaziosmanpaşa Üniversitesi Ziraat Fakültesi yayınları No: 15 Kitap Serisi: 8.

Parker, C., Riches, CR. 1993. Parasitic Weeds of the World. Biologyand Control. CAB International, Wallingford. Phytotaxin, (5): 443-445.

Restuccia, A., Marchese, M., Auromicale, G., Restuccia, G. 2009. Biological Characteristics and Control of Orobanche crenata Forsk., a Review, Ital. J. Agron. / Riv. Agron., 2009, 1:53-68.

Rubiales, D., Fernandez-Aparicio, M., Haddad, A. 2009. Parasitic weeds. The Lentil Botany, Production and Uses. Editedby William Erskine, Fred Muehlbauer, Ashutosh Sarkerand Barlam Sharma. CAB International, 343-349.

Sırrı, M. 2019. Siirt ili fistık bahçelerinde görülen yabancı otların yaygınlık ve yoğunluklarının belirlenmesi, Bitki Koruma Bülteni / Plant Protection Bulletin, 59(3):3-14.

Sirrı, M. 2020. Siirt ili mercimek (Lens culinaris medic.) ekim alanlarında sorun oluşturan yabanc1 ot türlerinin yoğunluk ve rastlanma sıklıklarının belirlenmesi.
Kahramanmaraş Sütçü İmam Üniversitesi Tarım ve Doğa Dergisi, 23 (1): 117-126.

Tepe, I. 1998. Türkiye'de tarım ve tarım dışı alanlarda sorun olan yabancı otlar ve mücadeleleri. Yüzüncü Y1l Üniversitesi Yayınları No: 32, Ziraat Fak. Yayınları No:18, 86s.

Uludağ, A., Demirci, M. 2005. The Orobanche problem in Turkey and its economic impact. COST Action 849, Parasitic plant management in sustainable agriculture $w g 1+4$ workshop on means forlimiting Orobanche propagation and dispersal in agricultur alfields, 4-6 December 2005, Israel, 13.

Uludağ, A., Demir, A. 1997. Güneydoğu Anadolu Bölgesi'nde mercimek alanlarında bulunan parazit yabancı otlar. Türkiye II. Herboloji Kongresi, 1-4 Eylül 1997, İzmir.

Yıldırım S., Tepe I. (2014). Van'da Yoncada Küçük Tohumlu Yonca Küskütü (Cuscuta approximata Bab.)'nün Dağılımı ve Yoğunluğu. Yüzüncü Yıl Üniversitesi Tarım Bilimleri Dergisi. 24 (1): 42-50.

Zeybek, N. 1958. Farmasötik botanik, kapalı tohumlu bitkiler (Angiospemae) sistematiği ve önemli maddeleri. Ege Üniv. Ecz. Fak., No: 1, Ege Üniv. Basını evi, İzmir, 390s. 